wound haring then soundly healed. It is difficult to surmise what may have been the precise origin of this unusual band, for there had been no history of pelvic trouble and the band itself lay entirely outside the pelvis. I have nerer seen an abdominal band at all as firm as this, and it was a fortunate event for the woman that it was divided before the bowel had been itself damaged. The history shows how indefinite and obscure were the symptoms and how operation alone could have relieved them. So fine, however, was the band, that had it not been for the sulcus in the bowel it might perchance have been missed - an accident which I know to have occurred in another case with somewhat like symptoms, unfortunately postponing thereby a second operation for the relief of complete obstruction until it was too late. The practical lesson to be learned from the case is thus suffciently obvious.

CASE 2.-This case was one of the most acute obstrucuion with symptoms of extreme urgency. A man, aged fifty-nine years, was admitted to St. Mary's Hospital on March 8th, 1898. On the early morning of the 7 th he was seized with great pain at the umbilicus while at stool-pain which rapidly became so much worse that he was obliged to lieave his work and send for a medical man. In the afternoon he vomited frequently. After 10 A.M. he passed neither fæces nor flatus. On admission to the hospital at midday of the 8th he had a most anxious, ghastly expression; his face and lips Nere blue, his mouth was parched, he had intense griping pains all over the abdomen, he was well-nigh pulseless, and was almost continuously sick. The abdominal wall was rigid, but there was no marked distension. Nothing could be felt on palpation. The nature of his symptoms admitted of no doubt and he was taken at once to the theatre. The abdomen having been opened in the middle line, systematic examination of the bowel from below upwards ultimately led to the discovery of a coil of jejunum some six inches in length, of a deep plum colour, constricted by a fine band three or four inches long, and running from omentum to omentum. It was easily torn through with the finger and did not bleed. Flatus immediately passed onwards into the empty gut below. The coil of ensnared bowel was smooth and free from lymph-there was indeed no effusion of lymph anywhere-and there was no fear that it would not perfectly mecorer itself. So much and no more would have been necessary in the way of operation had not the peritoneal cavity contained a large quantity of blood-stained serum-so much, in fact, that it was deemed absolutely essential to remove it, and this was forthwith done by washing out the cavity with a saline solution. Just as a hernial sac is sometimes found to contain blood-stained serum when bowel has been strangulated within it, so here the peritoneum took the place of a hernial sac into which unusual quantities of Blood-stained serum had been effused. The wound was closed in the usual way, and thereafter the patient made steady progress to recovery. His course throughout gave little or no anxiety; the romiting soon ceased and his bowels were in due time moved, his only trouble being the most intense thirst for three or four days after the operation, due in no small measure, it may be conceived, to the loss of fluids both by the vomiting and the peritoneal effusion. He was discharged on May 5 th. For the notes of this case I have to thank Mr. Hussey.

The operation was in this case singularly free from difficulty because of the fact that the constricted bowel was high up and the greater portion of small intestine was flaccid and empty. But the site of the strangulation no doubt determined the initial severity of the symptoms, which in their turn contributed to that which was the most prominent feature in the case-the extraordinary amount of peritoneal effusion. This, again, in turn conduced to the serious condition of the patient, which was clearly one of acute toxæmia from which death was imminent. The peritoneum presented none of the grosser visible signs of peritonitis, but the man was nevertheless dying, surely not from the mere fact that a short length of bowel was ensnared by a band but because doses of poison leveloped in his own peritoneum-and in all probability of the most virulent kind-were being rapidly absorbed into his system. There was never a more striking case. "There is about the patient who is dying of peritonitis every suggestion of a poisoned man. He lies in bed prostrate, with gaunt cheeks and sunken eyes. There is a look of unceasing anxiousness in his face and a sense of hopeless unquiet in his movements. The hands, which wander with pathetic restlessness over the bedolothes, are cold and damp. The tongue is that of a man who is dying of thirst. There is constant vomiting. The breathing is laboured and accompanied with faint sighs and groans, and the countenance is ashen and livid." This is the picture drawn by Treves in his lectures on Peritonitis, ${ }^{1}$ and it is eminently suggestive of death by poison. To clear away the source of the poison in the peritoneum must, then, be the surgeon's aim, and it may with truth be said that there is probably no condition in which it is so essential to wash and cleanse the peritoneal cavity of any effusion there may be in it, or in which it is so necessary to disregard, and not be misled by, the absence of the grosser indications of "peritonitis" if the best is to be done for the patient in a case like this at the time of operation.

\section{THE VALUE OF ANTI-STREPTOCOCCIC SERUM IN THE TREATMENT OF SOME PATHOGENIC INFECTIONS.}

By NATHAN RAW, M.D., B.S. DURH., F.R.C.S. EdIN., MEDICAI SUPIRIXTENDHYT, MYLL-ROAD INFIRMARY, LIVERPOOL.

So many conflicting statements have been made in the medical journals of late regarding the efficacy and real value of anti-streptococcic serum that I determined to give it an extended and thorough trial in those diseases which were found on examination to be due to infection by the streptococci. In THE LANCEN of Feb. 19th, 1898, I recorded a case of puerperal septicæmia in which the patient's life was, in my opinion, saved by this treatment and I then sounded a note of warning against the indiscriminate practice of injecting all cases of septic infection with this powerful remedy. From the very nature of things the serum can only be of service in streptococcal infections and ought never to be used until either the microscope or bacteriological examination has shown streptococci to be present in the blood or discharge. The cases under my care in which the serum has been used are 11 in number-namely, 4 cases of puerperal septicæmia, 2 cases of septic cellulitis, 2 cases of mastoid disease with septicæmia, 2 cases of erysipelas, and 1 case of puerperal sapræmia.

CASE 1.-A married woman, aged twenty-two years, a primipara, was admitted to the infirmary on Oct. 31st, 1897. suffering from puerperal septicæmia. She had been delivered 15 days previously, having been attended by a midwife. The patient's temperature was $106^{\circ} \mathrm{F}$. and the pulse was 146. She was quite unconscious and wildly delirious. I curetted the uterus, removing a large quantity of placenta and stinking débris. On examination of this it was found to be swarming with streptococci which were also found in the blood. Injections of serum (20 c.c. as a dose) were given at intervals with marked effect. The temperature was reduced, the delirium abated, the patient became conscious, and the pulse was reduced in rate and altogether much improved. In all she had 60 c.c. of serum in four injections and made an excellent recovery.

CASE 2.-A woman, aged thirty years, was admitted to the infirmary on Nov. 8th. She had been confined of a stillborn child on Oct. 28th, having been attended by a midwife The labour was prolonged, lasting a week; 3 days later she became delirious. On admission the temperature was $103^{\circ} \mathrm{F}$. and the patient had all the symptoms of puerperal septicæmia. Microscopic examination showed that streptococci were present both in the blood and in the discharge from the uterus. On Nov. 25th the patient was put under chloroform and the uterus was scraped out and 10 c.c. of serum were injected; the temperature dropped to $101^{\circ}$ and she felt much better. She, however, developed septic pleurisy and died on Dec. 5th.

CasE 3.-A girl, aged fifteen years, was admitted to the infirmary on Dec. 30th, 1897, with a high temperature $\left(105^{\circ} \mathrm{F}.\right)$, loss of consciousness, and acnte delirium. She had a purulent discharge from the left ear and all the symptoms of mastoid abscess with meningitis. On the 31st the mastoid antrum was cleared of a lot of offensive pus and I made a free communication between the middle-ear and external 
meatus. The pus from the middle-ear was full of streptomeatus. The pus from the middle-ear was full of strepto-
cocci. 20 c.c. of serum were injected with an excellent result, the temperature dropped in a few hours, the headache was better, the skin was moist, and the pulse was rerluced. She, however, developed septic pleurisy and died on Jan. 1st, 1898. At the post-mortem examination it was found that the lateral sinus and internal jugular were thrombosed and contained stinking thrombi.

CASE 4.-A girl, aged nineteen years, was admitted to the infirmary on $\mathrm{Jan}$. 26th, 1898, with a temperature of $105^{\circ} \mathrm{F}$. suffering from a most acute attack of erysipelas which involved the head, neck, and chest. The temperature remained between $104^{\circ}$ and $105^{\circ}$ for 5 days and the girl was in a very critical condition. Examination showed that the blood was swarming with streptococci. 20 c.c. of serum were given on Jan. 30th with a most astonishing result. The temperature dropped to $100^{\circ}$ in 5 hours and the patient was more conscious and felt relieved. The temperature again rose to $105^{\circ}$ on the next day and another 20 c.c. of serum were given, with the result that it dropped in five hours to normal. It again rose next day to $104^{\circ}$, when 20 c.c. of serum were given, bringing down the temperature to $101^{\circ}$ and the pulse from 140 to 110 . The patient had another injection on Feb. 2nd of 20 c.c. of serum, after which the symptoms subsided and she made an excellent recovery. The patient had in all 80 c.c.

CASE 5.-A woman, aged thirty-five years, was admitted to the infirmary on Feb. 19th with septic cellulitis of the hand and arm extending to the elbow. It had a foul and gangrenous smell and was rapidly extending. Examination of the pus showed the presence of streptococci. Under chloroform I made free incisions and removed all the sloughing material and at the same time injecter 20 c.c. of serum into the affected arm. The result was magical : the arm quickly quieted down and the patient made a good recovery with a useful arm.

CAsE 6.-A woman, aged forty-six years, was admitted to the infirmary with septic cellulitis of the arm following an injury by a rusty nail. She was extremely ill, the wristjoint was suppurating, and she had septicæmia. I laid open the joint and incised the arm and injected 20 c.c. of serum. She improved considerably, but eventually succumbed to an attack of septic pericarditis.

CASE 7.-A girl, aged seventeen years, was admitted to the infirmary on March 10th, 1898, with all the symptoms of mastoid abscess and meningitis. Her temperature was $104^{\circ} \mathrm{F}$. and she had a fœtid discharge from her left ear on March 11th. I trephined the mastoid antrum and made a free communication with the external meatus, clearing out a lot of stinking pus. At the operation I injected 20 c.c. of serum. On the following day she was conscious and her temperature dropped to normal. She afterwards had three injections of $10 \mathrm{c.c}$. of serum each and although she had a prolonged attack of meningitis she made an excellent recovery. Her blood contained streptococci.

CASE 8.-A woman, aged thirty years, was admitted to the infirmary on March 19th suffering from puerperal septicremia. She had been confined a week previously of a child and attended by a midwife. The uterus was scraped out and 20 c.c. of serum were given three times, making in all 60 c.c. After each injection she was relieved, the temperature dropped, the pulse became slower, and her headlache and pain were relieved. She developed, however, septic pleurisy and pericarditis and died on March 24th.

CASE 9.-A woman, aged thirty-four years, was admitted into the insane wards of the infirmary on April 17th with puerperal mania. She had a temperature of $102^{\circ} \mathrm{F}$, which rapidly rose to $105^{\circ}$, with all the symptoms of septicæmia. Under chloroform I curetted the uterus and intra-uterine louches of mercuric chloride were given. Plate cultures were made of the blood and uterine discharge which showed an almost pure cultivation of streptococci. 10 c.c. of serum were given on the 21st with a good result. She had numerous complications in the form of abscesses and infective periostitis of the femur, which were opened and drained under anæsthetics. In all she had 90 c.c. of serum, which in my opinion saved her life, as I have never seen a inore complicated case.

CAst 10.-A woman, aged twenty-five years, was admitted to the infirmary on May 26th with all the symptoms of puerperal septicæmia with profound anæmia. She was delivered of a child a week before admission with placenta prævia. On admission her temperature was $105^{\circ} \mathrm{F}$. and she was in a most serious condition. Under chloroform I curetted the uterus and moved nearly $2 \mathrm{oz}$. of stinking placenta and clebris. $O_{1}$ making plate cultivations of both the blood and uterine rischarge no streptococci could be found, but numerous staphy. cocci, both aureus and albus; before the result of the bacteriological examination was known I injected 20 c.c. of serum (Pasteur's). The good result noted in the previoucases was not seen here, the temperature remained hioh and no further injections were given. The patient lingered until June 21st, when she died from septic pleurisy anc thrombosis. Post mortem a very careful bacteriologica examination was made of the organs. Cultivations on Petri dishes were made from the uterus, kidneys, and lungs. and all showed a complete absence of streptococci, but numerou:staphylococci and bacilli coli communes were present. The uterus was found to be almost smooth and she had septic pleuro-pneumonia.

CASE 11.-A woman, aged fifty-two years, was aclmitter to the infirmary on Jume 24th with an acute attack o erysipelas, the temperature being $105^{\circ} \mathrm{F}$. She was giv' 20 c.c. of serum with a most excellent result and completely recovered.

The above series of 11 most acute and severe infections by streptococci show 6 recoveries and 5 deaths. This is, admit, not a very large percentage of recoveries, but it wust be borne in mind that only the most acute and dangerou cases were submitted to the treatment. The most difficul part of the treatment is to determine the exact nature of the infection, whether it is due to the various forms of strepto cocci, or to staphylococci, or to a mixed infection of all thes organisms. The bacillus coli communis is repeatedly found here, rarely alone, but generally with staphylococcus aureus whether or not it is the same organism as the bacillus pyogenes fotidus is a matter of uncertainty. My routint practice now is to at once submit the blood or discharge from any case of acute infection to a bacteriological examination in the laboratory, and if the presence of streptococci is demonstrated clearly to at once inject the sermm If the streptococci are not found the serum can be of $n$ possible service, as was well shown in Case 10.

Much has yet to be done to elucidate the exact bacterio logy of the various forms of sepsis and especially to sevarate and individualise the streptococci. The Pasteur Institute have succeeded in obtaining an anti-streptococcic serum by injecting pure toxins, thus placing it on the same basis a anti-diphtheritic serum, but at present the composition is a secret. If this is accomplished I feel sure it will be a grea step in advance in the treatment of pyogenic infections From a careful and prolonged use of the serum I feel convinced of its efficacy in the streptococcal infections such as puerperal septicæmia, septic cellulitis, erysipelas, and septicmeningitis from middle-ear disease. The serum I now ust is supplied by any druggist and is obtained from the Pastem Institute in fluid form, as I find it more pure and free fron: errors in filtration. I have never seen any bad symptom. from the use of the Pasteur serum if obtained comparatively fresh and injected with antiseptic precautions. The dost I prefer is $20 \mathrm{c.c}$. In conclusion, I have to express my thanks to my colleagues, Mr. German and Dr. Christopher: for their useful assistance.

Liverpool.

\section{A NOTE UPON A CASE OF ABDOMINAL SECTION IN WHICH STERILE BROTH WAS INJECTED INTO THE PERI- TONEAL CAVITY PRE- VIOUSLY TO OPERATION.}

By J. W. WASHBOURN, M.D., F.R.C.P. LoND. PHYSICIAN TO THE LONDON FEVER HOSPITAL; ASSISTANT PHYSICIAY TO GUY'S HOSPITAL, \&C.

DR. H. F. DURHAM, in an interesting paper upon the Clinical Bearing of some Experiments on Peritoneal Infections, ${ }^{1}$ suggested a preliminary treatment of the peritoneuns in operations upon the abdomen when there is a risk of contamination ensuing. The treatment he recommender

1 Transactions of the Royal Medical and Chirurgical Society, Fol. 1xxx., Part II., p. 191 . 